\title{
Lung volume reduction in real clinical practice
}

\author{
Jorine E. Hartman (10 ${ }^{1,2}$ and Dirk-Jan Slebos (1) ${ }^{1,2}$
}

${ }^{1}$ Dept of Pulmonary Diseases, University of Groningen, University Medical Centre Groningen, Groningen, The Netherlands. ${ }^{2}$ Groningen Research Institute for Asthma and COPD, University of Groningen, University Medical Centre Groningen, Groningen, The Netherlands.

Correspondence: Jorine E. Hartman, Dept of Pulmonary Diseases AA11, University Medical Center Groningen, PO Box 30001, 9700 RB Groningen, The Netherlands. E-mail: j.hartmandumcg.nl

$@$ ERSpublications

Pragmatic studies and capturing routine care clinical data in registration databases are important to further guide and optimise treatments in the future https://bit.ly/3el1lh7

Cite this article as: Hartman JE, Slebos D-J. Lung volume reduction in real clinical practice. ERJ Open Res 2021; 7: 00258-2021 [https://doi.org/10.1183/23120541.00258-2021].

Lung volume reduction options for severe emphysema patients are more and more recognised as a valid treatment option. In this issue of ERJ Open Research, Dooms et al. [1] present the results of a single centre cohort study which evaluated endobronchial valve (EBV) treatment and compared it with patients who were not eligible to undergo the treatment due to collateral ventilation. Afterwards, the patients who were not candidates for EBV treatment and the non-responders to the EBV treatment were evaluated, and if eligible, treated with surgical lung volume reduction (LVRS). With this design, the authors tried to combine and present multiple studies in one article, which made the study complex and difficult to draw conclusions from. However, the study does describe the current clinical practice with regards to the choice and potential order of bronchoscopic or LVRS treatments in patients with severe emphysema, which go hand in hand, and therefore is helpful in the guidance of routine care.

More than a decade ago, bronchoscopic lung volume reduction treatment using endobronchial valves was developed as a less invasive alternative to LVRS. Multiple randomised controlled trials showed that patients can clinically benefit from the treatment [2], which led to its inclusion in the Global Initiative for Chronic Obstructive Lung Disease guidelines in 2017 [3] and consequently the implementation of the treatment in regular care worldwide. The transition to regular care also came with new challenges [2], two of which are addressed by Dooms et al. [1].

The first challenge is the positioning of EBV versus LVRS. Not all patients that are good candidates for EBV are good candidates for LVRS and vice versa, and currently there are no published studies that have investigated the direct comparison of both treatments. Currently, the CELEB trial is underway in the UK investigating this comparison [4], and the results of this study could lead to more concrete decision-making guidance for candidate patients for both techniques, in addition to the guidance described in literature to date $[5,6]$. However, it is questionable how many patients with similar characteristics are actually eligible for both interventions. This group would consist of the small group of emphysema patients, with a perfect treatment target lung lobe, being suitable for both valves and surgery. Furthermore, a lot of patients will not be considered for surgery due to severely impaired lung function or exercise capacity, high age, or comorbidities. The choice of Dooms et al. [1] to first reduce lung volume per bronchoscope in patients who are eligible for both lung volume reduction techniques is preferable as the EBVs can be removed and thus the treatment is reversible. Therefore, EBV treatment would be the first choice of treatment and in cases where it is not successful, LVRS could follow. An additional benefit of this strategy could be that the clinical effect of the reduction in lung volume is "tested". For example,

Received: 13 April 2021 | Accepted: 15 April 2021

Copyright $\odot$ The authors 2021. This version is distributed under the terms of the Creative Commons Attribution NonCommercial Licence 4.0. For commercial reproduction rights and permissions contact permissions@ersnet.org 
patients who are initial good responders to EBV treatment, but who develop granulation tissue, a known complication of the treatment [7], already have shown that they can benefit from lung volume reduction. In contrast, patients who did not benefit from the bronchoscopic lung volume reduction will potentially also not benefit from the surgical alternative. Dooms et al. [1] showed that patients can benefit from LVRS in terms of lung function, exercise capacity and quality of life. However, most patients who underwent LVRS in this study were actually patients who were not eligible for EBV due to collateral ventilation $(n=13)$ and only two patients were EBV treatment non-responders. The results from these two patients are too limited to draw any conclusions on the benefit of LVRS versus EBV treatment. EIchHorN et al. [8] did investigate the effect of LVRS after EBV treatment in patients who had an initial but not sustained effect of the EBV treatment. The authors concluded that this patient group can benefit from LVRS after a failure of an initial good response to the EBV treatment. This underlines the potential of a step-up treatment approach for initial good responders to EBV treatment. In the study by Dooms et al. [1] all patients who underwent LVRS underwent bilateral upper lobe shaving, which is the classic LVRS technique. For those patients who are eligible for EBV treatment, with a single destroyed lobe, an anatomical lobectomy could also be performed. By contrast, patients with paraseptal emphysema who are not eligible for EBV treatment could be eligible for the classic shaving LVRS technique. Therefore, the type of emphysema is important for the choice of the preferred lung volume reduction technique.

Another challenge of the implementation of EBV treatment in regular care that Dooms et al. [1] address is the combination of EBV treatment and the guidance on the ability to increase physical activity after treatment. In the presented study all patients underwent a physical activity coaching programme between 3 and 6 months, which could be a valuable addition to the after care of EBV treatment as the patients' most limiting factor for physical activity, hyperinflation, has been significantly reduced. Unfortunately, in this study the addition of this programme makes the interpretation of the effects between groups even more complicated as it is not clear what additional effect this coaching programme had. When looking at the change in 6-min walking distance in the non-EBV group, in general the effect of this programme on exercise capacity seems limited. It would be interesting to investigate the effect of this kind of programme or a structured physical therapy or pulmonary rehabilitation programme after EBV treatment in a controlled study design [9].

In general, the paper does show the importance of a multidisciplinary team when evaluating the treatment options for these severe emphysema patients $[10,11]$. Careful patient selection for the different treatment options is very important for treatment success and including different disciplines in the multidisciplinary team emphysema expert meeting is key to ideal treatment allocation. This meeting could even be expanded when including more disciplines and treatment options like in a recently described multidimensional respiratory failure meeting [12]. Consequently, this indicates that it is important to have specialised emphysema treatment centres who have experience with the disease and have access to the different treatment options, which will lead to the potential most ideal treatment option for the patient.

To conclude, the study by Dooms et al. [1] is an elegant example of the implementation of lung volume reduction treatments in daily clinical practice and shows that it is difficult to capture this in a clinical trial. This kind of pragmatic study or capturing routine care clinical data in registration databases are important to further guide and optimise these treatments in the future.

Conflict of interest: J.E. Hartman has nothing to disclose. D-J. Slebos reports grants, personal fees, and nonfinancial and other support from PulmonX Corp, USA, PneumRx/BTG, USA; grants, and nonfinancial and other support from Nuvaira, USA, and CSA Medical, USA; and grants and other support from FreeFlowMedical, all outside the submitted work.

\section{References}

1 Dooms C, Blondeel A, Ceulemans L, et al. Lung volume reduction in emphysema: a pragmatic prospective cohort study. ERJ Open Res 2021; 7: 00877-2020.

2 Hartman JE, Vanfleteren LEGW, van Rikxoort EM, et al. Endobronchial valves for severe emphysema. Eur Respir Rev 2019; 28: 180121.

3 Vogelmeier CF, Criner GJ, Martinez FJ, et al. Global strategy for the diagnosis, management, and prevention of chronic obstructive lung disease 2017 report. GOLD executive summary. Am J Respir Crit Care Med 2017; 195: 557-582.

4 Buttery S, Kemp SV, Shah PL, et al. CELEB trial: comparative effectiveness of lung volume reduction surgery for Emphysema and Bronchoscopic lung volume reduction with valve placement: a protocol for a randomised controlled trial. BMJ Open 2018; 8: e021368.

5 Gordon M, Duffy S, Criner GJ. Lung volume reduction surgery or bronchoscopic lung volume reduction: is there an algorithm for allocation? J Thorac Dis 2018; 10: S2816-S2823.

6 Herth FJF, Slebos D-J, Criner GJ, et al. Endoscopic lung volume reduction: an expert panel recommendation update 2019. Respiration 2019; 97: 548-557. 
7 Koster TD, Klooster K, Ten Hacken NHT, et al. Endobronchial valve therapy for severe emphysema: an overview of valve-related complications and its management. Expert Rev Respir Med 2020; 14: 1235-1247.

8 Eichhorn ME, Gompelmann D, Hoffmann H, et al. Consolidating lung volume reduction surgery after endoscopic lung volume reduction failure. Ann Thorac Surg 2021; 111: 1858-1865.

9 Hartman JE, Vanfleteren LEGW, Van Rikxoort EM, et al. Bronchoscopic lung volume reduction treatment using endobronchial valves for emphysema: emerging questions. Respiration 2018; 96: 588-589.

10 Chew J, Mahadeva R. The role of a multidisciplinary severe chronic obstructive pulmonary disease hyperinflation service in patient selection for lung volume reduction. J Thorac Dis 2018; 10: S3335-S3343.

11 Hartman JE, Klooster K, Slebos DJ. From bench to bedside: implementation of endobronchial valve treatment for patients with advanced emphysema in routine clinical care. Respiration 2019; 99: 187-188.

12 van Dijk M, Gan CT, Koster TD, et al. Treatment of severe stable COPD: the multidimensional approach of treatable traits. ERJ Open Res 2020; 6: 00322-02019. 